\title{
Strategies for information management in education: Some international experience
}

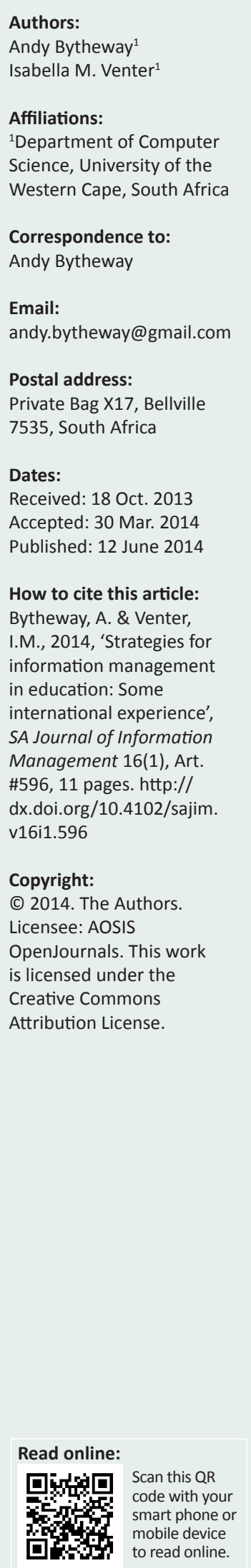

Background: Recent analysis of the management of information and communications technologies in South African education suggests strongly that there is only limited strategic thinking that might guide policy-makers, school principals, teachers, learners and suppliers of educational technologies. It is clear that here in South Africa, as elsewhere, the actual practice of technology-mediated education is driven more by the available technologies than by actual learner needs, good management principles and the wider national imperative. There might be lessons to be learned from experience elsewhere.

Objectives: This article reports and analyses conversation with eight international educators in Europe, Canada, the United States, New Zealand and Australia. All are managing the impact of technology in different ways (reactive and pro-active), at different levels (pre-primary through to senior citizen), in different roles (teachers, administrators and senior managers) and in different contexts (schools and universities).

Method: Open-ended conversations with educators and educational administrators in developed countries were recorded, transcribed and analysed. The qualitative analysis of the content was done in the style of 'open coding' and 'selective coding' using a qualitative content analysis tool.

Results: Whilst technology is still seen to drive much thinking, it is found that that success is not derived from the technology, but from a full and proper understanding of the needs and aspirations of those who are directly involved in educational processes, and by means of a managerial focus that properly recognises the context within which an institution exists.

Conclusion: Whilst this result might be expected, the detailed analysis of the findings further reveals the need to manage investments in educational technologies at different levels and in different ways.

\section{Introduction}

Education is rapidly becoming digitised at all levels, including the production, dissemination and transfer of knowledge. Despite the clear need for educators and learners to share knowledge, it is interesting that the initial impetus for introducing information technology (IT) into education often comes from the technology itself rather than from educational need. This can be seen as 'technology push', as opposed to the 'educational pull' that arises from a proper articulation of the needs of different educational activities and subjects (Anderson et al. 2002; Baker-Eveleth et al. 2007; Barron et al. 2003). The technology push-pull arguments have prevailed for decades in business and the public sector, but it is now widely recognised and agreed that information and communications technology (ICT) investments should be justified on the basis of the benefits that will be gained (Ward \& Daniel 2005). It follows that the benefits of ICT investments must be effectively managed in education, as they are elsewhere; as Ward and Daniel argue: in education (as in any kind of enterprise) the 'pull' is more important than the 'push'; managing information promises more benefit than managing information technology.

But, what exactly is it that sits between the achievement of the benefits of good information management and the technology that underpins it? And what is meant by information management'?

These are questions that all managers must ask, even in education. It is therefore surprising to find a lack of specific research into the management of ICT in education, despite the fact that these are times of great technology-induced change (Botha 2009; Motala 2009; Bytheway 2013). Change is happening fundamentally at the level of social behaviour (Angell 2000; Shirky 2008), and in education and knowledge management in South Africa and elsewhere (Moloi 2007; Omona, Van der Weide \& Lubega 2010). In reading educational research, the word 'management' is not often 
found: a review of more than 700 articles published over the last 20 years found very few that specifically addressed the management of information technology and information systems in education; some are old and many are from developed regions of the world (Michael 1998); some point clearly to practice in regular management in business in order to find answers (Uys 2007:239), others argue for the use of systems analysis methods (Hardman \& Paucar-Caceres 2010:168) or they verge on speculation (Bhusry \& Ranjan 2012:315). When management is mentioned, it is often to decry the problems created by 'management', as if managers were separate from the real world of educational practice.

Of course, the degree of 'push' and 'pull' and the nature of the needed benefits depend on the context. In different countries significantly different levels of achievement might be found. For example, in Singapore it is now more than 25 years since the introduction of a system through which parents could check, each day, what their children had learned at school, using their television set linked up to the local education management systems - and that was before the general availability of the world wide web (Maslin 1990). At the other end of the scale, education in South Africa, a developing country, is reported to be in a precarious condition (Jansen 2012). In spite of many experts' belief that the introduction of ICTs into education will solve problems, experience with educational ICT initiatives in South Africa is variable, according to local research undertaken at different levels (Brown 2010; Bytheway 2004, Bytheway et al. 2010; Davids 2009; Koch 2006; Madiba 2009; Republic of South Africa 2004). A special problem is the induction of disadvantaged students with only a rural background, where cultural issues can present special challenges and where a free association with technology is found to be helpful to those students (Rahimi 2010). The educational 'pull' in a vibrant and successful context such as Singapore will have little in common with the needs of impoverished rural regions of Africa, where there might be no electricity and no data communications services.

In much of the expert analysis that is available, there is little that specifically addresses the management of information at a strategic level, or even at a systems level. The focus is commonly on pedagogy, didactics, specific technologies or contextual and social issues. The question arises: do we need to widen our viewpoint, and examine the educational processes and information resources that can be improved by better information management, rather than the generalities of context or the specifics of information technology? Hence, the central problem addressed here is that the benefits of technology investments in education are not realised in South Africa.

The problems in South Africa, and the evident belief that information technology offers solutions to some of our problems but has not really delivered them, partly because of the dependency on teacher attitudes (Chigona et al. 2011), led to the idea of a review of international experience with and attitudes to the management of digitised information and of information technology in education, by means of conversations with educators and administrators working in international education. This article explores how information technology is typically managed in selected countries, by an analysis of eight international conversations with educators and administrators that set out to explore the extent to which information and information technology are managed strategically in education, with what benefits to stakeholders.

Firstly, the article reviews the strategic management of information technology from a general perspective, drawing on theories from business management; a generic framework for the analysis of strategic alignment is introduced and then used to organise an open coding of the qualitative data derived from the eight conversations. A further selective coding and stakeholder analysis then examines the benefits of ICTs in education according to the different stakeholder groups, the benefits that they seek and the extent to which strategic planning might help.

The question at the heart of this work is: does strategic planning help to deliver the benefits of information management in education? As will become evident, 'information management' is considered to include a range of management activity, from technology through to strategy.

\section{Strategic management of ICTs}

There is extensive literature on strategic planning; in progressive businesses it is routine to undertake periodic analysis of internal and external challenges and opportunities, especially those relating to ICTs. The challenges and opportunities arising from information technology are a feature of much of that literature, but all organisations still find it difficult to achieve the anticipated results. Even in developed countries, in the public sector, huge amounts of money have been wasted in fruitless information technology projects (The London Independent 2010).

\section{Difficulty prevails}

Delivering benefits from any ICT investment is difficult, and it is all too easy to sweep failure under the 'carpet' of blamegames, shifting circumstances and general obfuscation about what is really needed. This is unfortunate, especially when there is such a long history of research and thought leadership about strategic information systems management. For at least 30 years this has been one of the hottest topics in the business research domain and its development can be traced over time (Zachman 1987; Baets 1992; Henderson \& Venkatraman 1993; Edwards \& Peppard 1997; Bytheway 1998; Luftman 2000; Kearns \& Lederer 2000; Ward \& Peppard 2002; Venkatesh et al. 2003; Ward \& Daniel 2005) Over time the scope of research has broadened, for example to deal with other contextual issues that constrain success, such as human factors and organisational politics, something that the typical IT manager seems to find very difficult (Knights \& Murray 1994; Chatham \& Patching 2000) 


\section{Strategic management of ICTs in education}

Strategic management is sometimes crudely reduced to a question with three parts: where are we now, where do we want to be and how shall we get there? The first real question, of course, is where do we want to be? This is where we debate and decide our objectives, the risks that are involved, the allocation of resources to strategic initiatives and so on. This then all depends on what people (those with influence) think about an organisation's strategic objectives and whether they perceive benefits that will accrue to their advantage. These influential people are the stakeholders, and these are the people we need to understand.

The remainder of this article presents an established framework for information management that joins issues of technology with issues of strategy and uses it to analyse the content of eight conversations with educators and educational administrators that illustrate how role-players in different countries are dealing with the management of ICTs in education. This provides some evidence with which to address the three questions above.

\section{A framework for information management}

During the 1990s, business managers and academics strove to find answers to critical questions about managing information in organisations. An early, extensive, review of literature concerning information systems 'success' was well received, is widely cited and has since been updated (DeLone \& McLean 1992, 2003). More recently (as noted) there has been increasing attention to the management of benefits rather than actual or perceived success, but huge problems are still evident even in developed, supposedly capable countries (Chatterji 2007; The London Independent 2010; Ward \& Daniel 2005). In the face of all this, how can the complexities of managing information in organisations be addressed?

\section{Frameworks emerge}

In the history of these matters, Zachman (1987) stands as a seminal source, but his frequently cited framework (a sixby-six matrix) was too complex for many managers to work with, having six layers of technology management down one side and six different perspectives on the business across the top: 36 different points of concern (the intersection of the six rows and six columns of the matrix) were just too many for many busy managers to handle.

Others have sought simpler views of the problem, and another frequently cited example is the Henderson and Venkatraman (1993) framework. It relates business and IT issues at the internal and external levels using a two-by-two matrix. This model is attractively simple at first sight, but it leads to a range of unanswered questions and lacks the elegance and symmetry that makes these things memorable. It implies dependencies and relationships between its conceptual components, but these are not immediately evident on a first reading, and as these authors admit in the original presentation of the idea, one has to go elsewhere to get the detail that is needed to operationalise the framework.

\section{The information management body of knowledge}

When these and other models are analysed and combined in order to understand what we need to be able to do well, a pattern emerges:

- Information technology: which comprises the requisite infrastructure for systems.

- Information systems: which support an organisation's operational processes.

- Organisational processes: which deliver benefits through improved performance.

- Organisational benefits: that are sought by stakeholders.

- Organisational strategy: that is realised by the delivery of required benefits (Bytheway 2004).

This arrangement of ideas has been developed, refined and tested. It is familiarly known as the 'IMBOK' (Information management body of knowledge). Recently it has been used to assess the perceived information management competencies of a large South African bank, and there is an archive of data from other sources that stands as a resource for future research (Bytheway 2011).

However, here we will use it in its simplest form, to provide a structure for the analysis of the international conversations. Figure 1 provides a simple overview.

As can be seen, the IMBOK framework divides the management domain into five (shaded) areas: technology, systems, processes, benefits and strategy. At the four intersections (the arrows) are the components of 'value' transfer and delivery: projects, process change, operations and performance; also, the imperatives: strategic imperatives, operational targets, user requirements and systems requirements.

So, to understand ways to maximise the benefits of investments in educational ICTs, we can now ask:

- What technologies are used in education?

- What systems assist education activities?

- What educational processes prevail and how are they changed by ICTs?

- What are the benefits and how are they measured?

- What strategies guide the use of ICTs in education?

\section{Method of working}

In a trip around the world, seven open-ended conversations with educators and educational administrators in developed countries were recorded (with permission) and have since

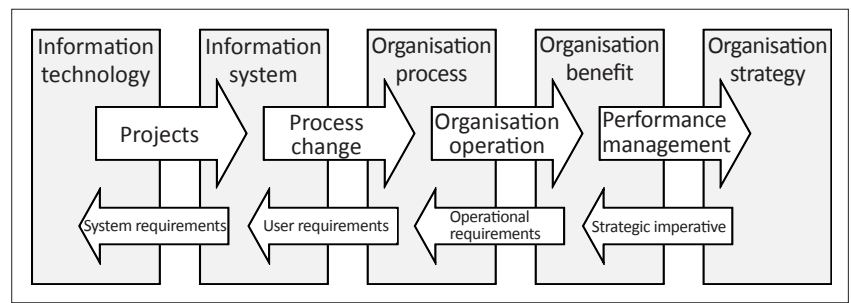

FIGURE 1: The information management body of knowledge (IMBOK). 
been transcribed and analysed; one later conversation with an education assessment consultant in the United Kingdom makes up the eight (see Table 1).

The general approach adopted for the analysis of the content was in the style of 'open coding' and 'selective coding' (Strauss \& Corbin 1998). Space precludes a detailed discussion of this qualitative approach to research, but the paragraphs below make it clear: they first present the open coding, by way of summary, and then the selective coding, based upon the domains of the IMBOK as described above.

\section{Open coding}

The first reading of the interview transcripts led to 26 a posteriori categories, as shown in Figure 2. On review, these categories were grouped into sets relating to:

- Activities of different kinds within education (principally administrative or educational).

- Contextual issues at the level of education, change and society at large

- The domains of the IMBOK.

- Issues open to further investigation.

- Resources of different kinds at different levels.

- Stakeholder references, indicating who is involved.

There was also a catch-all category of 'Others' that accommodated some of the academic references to theories of education and technology management.

The chart in Figure 2 tabulates the number of instances of coding of each category, across all of the interviews. Of course, to just count the frequency of occurrence of categories is a simple approach to analysis, but it provides a first view of the nature and content of the conversations and the focus of the respondents' interests.

As can be seen, a range of categories emerged from the open coding analysis, the most frequently occurring being information technology and the least frequent basic resources. Here we are principally concerned with those categories that map to the five layers of the IMBOK, as indicated by the 'IMBOK' prefix in the chart. Note therefore that the evidence presented here will be very selective because of the focus on the IMBOK as an analytical framework (and because of space constraints); the analysis does not represent the full richness of the 1139 actual instances of categorisation, and the 26768 words that comprise the substance of the eight conversations.

Interesting findings from the open coding include the following observations:

- Information technology drove much of the conversation, overriding issues of strategy, process, systems and (most worryingly?) benefits.

- There were many more problems than benefits articulated by the respondents.
TABLE 1: The eight conversations.

\begin{tabular}{lll}
\hline Person & Organisation & Location \\
\hline Engineer & Senior citizens club & California, USA \\
Technology teacher & High school & New Zealand \\
$\begin{array}{l}\text { Learning management system } \\
\text { manager }\end{array}$ & Business faculty & New Zealand \\
Senior academic & University & Ohio, USA \\
Teacher & Primary school & Minnesota, USA \\
Teacher & Kindergarten & Australia \\
Learning chair & Business school & Canada \\
Consultant & Education consultancy & York, UK \\
\hline
\end{tabular}

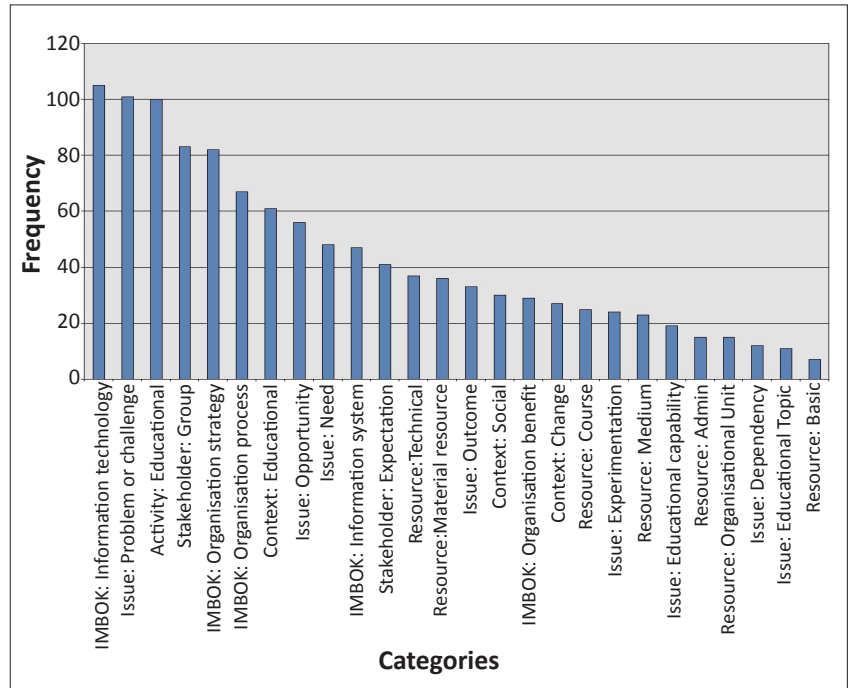

FIGURE 2: Open coding, 26 categories.

- As is often found in these kinds of conversation, discussion of technologies and problems were in the context of the educational processes and activities wherein they are found, rather than the deeper issues of benefits, experimentation and capability.

- Opportunities, needs, expectations and resources were all represented in the middle range of frequencies.

Hence, we find that there is a range of issues that extends from technology to strategic benefits, but the bias towards technology 'push' is strong.

The selective coding drives the analysis down into the issues of alignment, where we can see more clearly how information is managed, what benefits there are and whether there is any real strategic context within which management takes place.

\section{Selective coding}

From the 26 categories that emerged in the open coding, there are five relating directly to the five domains of the IMBOK:

- technology

- systems

- processes

- benefits

- strategies.

These five domains provide a useful framework with which to examine strategic management issues, and the principal portion of the analysis that follows is based on these five 
domains. It is useful to start by presenting the selected domains and their frequencies in the coding, this time in the same sequence in which the IMBOK presents them (see Figure 3). This allows us to see the extent to which the conversations dwelt upon these five principal domains. We can see these as five specific discourses within the general discourse about education and the way that information is managed therein.

In summary:

- As already noted, the most frequently occurring discourse concerned information technology. This (it can be argued) is inevitable, when conversation is predicated on the emergence of ICTs in education, but it cautions us that much conversation might be grounded in the availability and enticing capabilities of information technology rather than simple educational need - we come back yet again to issues of technology 'push' and 'pull'.

- Information systems did not figure greatly in the conversations; the very concept of an 'information system' or 'application' was almost completely absent. This contrasts with business and public sector working, when we frequently see references to the 'Payroll', 'ERP (enterprise resource planning)', 'CRM (customer relations management)' and other typical 'applications' that are to be found therein. When information systems are referred to in the conversations, the references are generally rather weak except (in just one case) when referring to the 'learning management system' (LMS).

- Organisational processes were discussed more often, partly because in conversations there is usually a bias towards 'what I do and how', rather than 'why'; there is some interesting evidence within this process discourse about how ICTs are affecting and changing what happens in education.

- The benefits of ICTs were infrequently referenced and were often tangential, being implied rather than being explicitly articulated. This helps us to understand a major part of the problem, because if the organisation at large does not perceive or understand (and then manage) the benefits, then all the benefits are as good as lost. A strong discourse on the intended benefits of an ICT investment is essential if managers are going to have clear targets to aim for.

- The strategy discourse emerged weakly, in different ways and from different perspectives, and once again strategic issues were mostly implied rather than clearly articulated. However, this indicates that the seeds of strategic thinking are there, and in fairness to all in education we already know that change can take a long time and is never easy.

The paragraphs that follow present selected evidence that exemplifies some of the stronger evidence that is to be found in the conversations.

\section{Who are the stakeholders?}

These eight wide-ranging conversations were not structured in any particular way, and it is inevitable that the evidence turns around the role of teachers, learners and management.
However, there is evidence of other critical stakeholders, and at the end of the day we have to remind ourselves that success comes from a balancing of all stakeholder expectations and an investment in resources and processes that will serve those expectations in a balanced way.

In the analysis of the conversations, there is evidence of 13 stakeholder groups, as indicated in Figure 4; of course, the frequencies of reference are not high enough, nor is the sample of respondents necessarily wide enough, to put a high level of significance on this result. Nevertheless, the analysis in the figure provides a clue as to which stakeholder groups might be the most important to consider, in the opinion of the respondents. And these stakeholder groups are not confined to teachers and learners, or students and professors; it is found that managers, communities, parents, administrators, other schools, suppliers and government are all factors in managing for success. A further investigation, in more detail, might reveal an even wider range of 'interested parties' and a better understanding of their relative importance, but we must assume that anyone, in any one of these stakeholder groups, could impact adversely on education in one or many educational institutions. When it comes to the adoption and integration of information technologies, it has been strongly argued that success will only emerge when the needs and expectations of all stakeholders are accommodated in the planning and implementation (Edwards \& Peppard 1997).

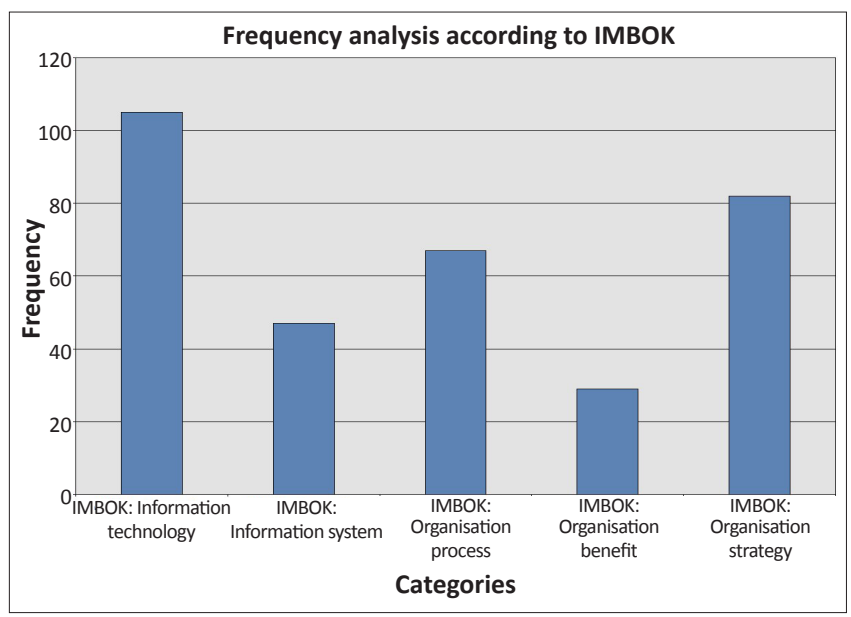

FIGURE 3: Category distribution by frequency.

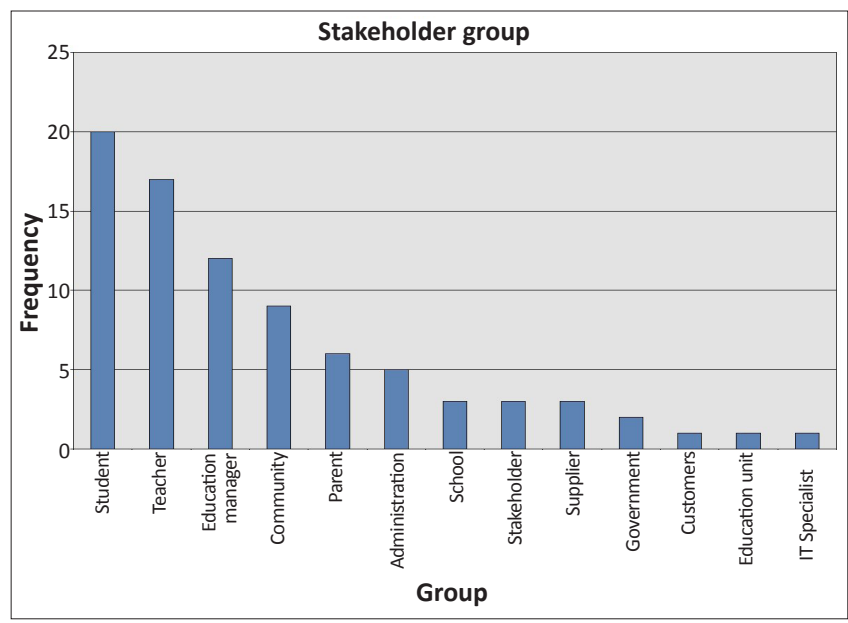

FIGURE 4: Stakeholder analysis. 
Thus, these are the stakeholder groups that need to be understood, whose expectations will set the criteria of success or failure and who might in their own way impact on the efforts of educators and educational managers to deliver the best results. Their expectations are not only defined in terms of the benefits that they recognise, but also defined by the benefits that they seek.

\section{Discussion}

Insights into the way that information management can affect the outcome of our investments in educational technology and our efforts to improve and advance our educational processes, and deliver strategic educational benefits, all come from a more detailed inspection of what was said by this diverse group of educators and administrators. The paragraphs that follow present selected evidence from the conversations, within the five domains of the IMBOK.

\section{Technology}

As we have seen, there is a range of technology that was talked about, but the educational benefits that technology brings were often more implied than expressed. Computers dominated the conversations and even concern about the variety of brands in use was evident. The systems within a brand (and the 'trendiness' of the systems) were also evident in terms of obsolescence and the preference for new rather than upgraded technologies:

'We've just introduced the iPads - we have six iPads, three of them are the new iPad 2, they came today .... at this time we use the 'blackboard' app where they can write their words or their sentences as if with chalk, rather than have a traditional slate in front of them'. [Teacher, Kindergarten, Australia]

The replacement of the low-cost chalkboard with a very expensive continuously evolving tablet technology might not be the first choice of a developing country. The 'electronic' or 'interactive' whiteboard is one example that is becoming more common and does seem to bring benefits, although there is still some learning to be done in terms of how it might best be used and how it might be fully integrated into educational practice:

'We have been networked, we have connected classrooms, which means that I can sit in the library with the interactive white board on, and have the television screen on, and talk to a class in [a different place altogether and] say [to our learners] "here is another school, what would you like to say to them?"' [Teacher, Kindergarten, Australia]

Apparently, today's learners are so attuned to looking at (and learning from) a screen that it really appeals to them - even 'special needs' children - and there might be clear benefits from building a relationship with a distant peer group, as hinted here. But it is not always easy for teaching staff to learn new technologies and applications at the same rate as their learners - sometimes there is simple resistance, even in higher education:

'Faculties [teaching staff] are the biggest resistance - the students' biggest complaint is that faculty won't use it enough: "we want to use the technology and you won't'. The faculty will say they don't have time'. [Learning Chair, University, Canada]

\section{Sometimes it all seems much too challenging:}

'Faculty need to be able to shift their way of thinking about the learning experience. So that's one part of that shift from the teaching paradigm - deliver information - to the learning paradigm ... so I see it as the duty of faculty to bring all these tools into the learning experience because it's like an apprenticeship process'. [Senior academic, University, USA]

Increasingly, students at higher education institutions choose (or are expected) to work with their laptops and not with pen and paper. One consequence is a whole additional layer of technology that requires a laboratory to be 'locked down' for an examination:

'We do some massive online testing. 220 students yesterday doing essay online in a lock-down exam, at the same time, in five labs ... we do a lot of lock-down, we actually use software to lock down the lab computers or even the student's own computers so they only have access to Blackboard, Turn-it-in. Some faculty adopt it, some don't'. [Learning Chair, Business school, Canada]

The complications of choosing to use technology accumulate as we do so. But at the institutional level some technologies are so basic that they are a 'must-have', otherwise students would simply choose to go to another institution with better facilities. Of course, understanding exactly which technologies qualify as 'important' is a strategic issue, not a technological issue. And between the technology and the achievement of strategic objectives come the information systems (or 'applications') that technology enables, and the processes that are enhanced by the systems.

\section{Information systems}

The more information-intensive areas of education showed very clearly how information systems are helping educators deal with large numbers of students and massive numbers of documents:

'Next term we will have nearly 2000 students in Business 101 and 102 , and these are all being taught in collaborative manner. So there are 20 tables of 6 students each, every hour, dealing with business problems - the students submit one paper and review six within three days, and that involves 12000 virtual copies of these papers going around and none getting lost'. [Learning management system manager, Business faculty, New Zealand]

Are there benefits from systems that handle such large numbers of students in this way? Probably, but detailed evidence of information systems that assist in education activities was actually limited. The balance of investment between administration and academic systems is a point of concern, and there is a tendency to invest in administrative systems first, although the connections with academic activity might be clear in specific cases:

'I actually did an administrative systems strategy for [the university] and they implemented most of it ... the area that we spent a lot of time on is academic support, administration of course management systems, and content'. [Learning Chair, Business school, Canada] 
Assessment of learning figured strongly in the conversations. Traditional modes of teaching, learning and assessment are changed by the use of technology. For example, traditional assessment by means of tests and examinations can be substituted by the use of 'discussion boards', another example of an information system:

'I teach a class on business and $15 \%$ of the evaluation is based on the discussion board. I post a topic every week and I rate them on the number of posts, the quality of posts. I also rate them on helping one another, and it's got to be timely'. [Learning Chair, Business school, Canada]

Of course, systems merely augment the propensities of their users: if people like to live with chaos then they can create even greater chaos; if they like to be organised, then they can be even more organised. If they like to keep things and not throw them away, they can keep more things for longer:

'I was asked on the ferry this morning 'Sir, are you the "father" of [the learning management system]?' and I said 'Well, one of them!' and he said 'I just came back to the university, I've been away five years and when I logged in everything is still there! All the classes were there that I took before, all my notes, all my stuff, that's an amazing system!' I said "that's the way we designed it"'. [Learning management system manager, Business faculty, New Zealand]

For a university that wants to distinguish itself, and stand out as a great place to work as well as to learn, this is the sort of thing that we are looking for. But, it's a pity when systems fail, in this case one that was not developed in-house but by 'experts':

'The [bought-in] system was absolutely airtight up until recently, however the output [from the new version] is not time-stamped and depending on the vagaries of the local network and so on you could get an enrolment before a deletion, or a deletion before enrolment, or the system could wind up just deleting the people out of the course and nobody knew where they went ... This was a $\$ 20 \mathrm{M}$ investment, hundreds of people involved, some of them making more than $\$ 100 \mathrm{k}$ per year, and it looks like we have to write our own middleware!'. [Learning management system manager, Business faculty, New Zealand]

The conversations highlighted the reality that fundamental systems-related changes are at hand. In discussing plagiarism, and what to do about it, Google and Wikipedia quickly come up in conversation, but do they count as 'systems'? Are 'Google docs' (an example of 'software-as-a-service') to be seen as 'systems'? We are reminded that we do not have to do everything for ourselves any more. Web-based services, combined with the myriads of 'apps' for iPads and Android tablets, guarantee that we will increasingly reach outside our boundaries in order to find the systems and services that we need, in open markets and at very low cost. But not all 'open' applications are small, and the tension between commercially available and open source systems is palpable:

'In 2009 we completed the transition [to Sakai] ... I think it was a wise investment. But that's an example where you have to convince people in leadership positions that you are doing the right thing. For the longest time they said, "you're gonna use open source? What are you gonna do when it breaks?" My answer is: "look at these other schools, we are in a community"'. [Senior academic, University, USA]

The use of learning management systems was a recurring feature of the conversations, but what about other important educational activity, such as research? The substance and mode of research working is changing rapidly. Where a doctoral thesis might once have had a few photographs or drawings pasted in on blank pages, or bound in at the end, today we expect the all-singing all-dancing presentation of everything (that we made move, or sing or dance) in our research to be immediately available in the digital archive. Taken overall, the effort involved in achieving technologyinduced change is keenly felt:

'So in a sense, by divesting some technology we take on new responsibility to guide and control the process and train people. And so we still need to look at all the assets that we have to make this happen, but to me I think it's a renaissance period for us, it's massive change, but it's so fun! It's like being on one of those roller coasters, you know? With the economic drag we felt like we were down here, but now we are going up again! It's really exciting, and a little scary'. [Senior academic, University, USA]

Clearly, this respondent is an optimist and an enthusiast. When it comes to changing the processes of education (dare we say 're-engineering' the processes?) things are not all that simple.

\section{Process}

Prevailing conventional education paradigms show signs of the impact of a developing technological world. Thus, knowing what goes on in a particular context is an important pre-requisite to understanding where an investment in technology might help. Tragically, the conversations reveal that learners are running ahead of many of the teachers, and teachers' control of teaching and learning processes is thereby threatened. Certainly the pace of change is a challenge that is more easily met by the learners (who have no 'baggage' to carry) than by the teachers, who are sometimes hidebound by their baggage. But when teachers choose to rise to the challenge there are rewards: 'It's amazing that the teachers create the content. It's the teachers that teach it so they are the ones to know what they want and what's good to learn' [Teacher, Kindergarten, Australia].

Not true of all, no doubt, but the liberation that comes from developing one's own material, as distinct from being told to teach from the 'standard' book that is chosen by some kind of educational authority, is a worthwhile reward for all positively oriented teachers, provided that they have the competency to deal with the pedagogical challenges that arise in designing and developing education programmes of different kinds.

New educational designs were evident in the high school in New Zealand:

'We've got a different setup in our school because we have what they call an open forum. There is no classroom. You teach in what we call a learning commons. What happens is, in a commons 
you can have four classes running at the same time. A common would be ... about the same size as this house. A class would be this size, so you would be here, and there next door (points to the kitchen) there would be another one. You can see them, hear them'. [Technology teacher, High school, New Zealand]

This was backed up by innovative use of cloud services, which are now an essential feature of learning at this school:

'I said to them, you are going to go into groups of five, the group leader is going to set up a Google doc and give you all editor rights, including me. The group leader is going to assign each person two sections and you are going to answer all the questions in your section. It worked quite well - you get a few stupid comments ... [but] one of the better students was a group leader and he basically blocked out two of the students in his group'. [Technology teacher, High school, New Zealand]

The use of Google Docs ${ }^{\mathrm{TM}}$ has since become more prevalent and the benefits (and other consequences) are becoming clearer. It is part of a move to make much more use of the social web in education. Close analysis of the evidence suggests a growing divergence between the formal and social aspects of educational processes; we must be aware of all the issues, and we must manage the change that will ensue in order to assure the benefits.

\section{Benefits}

We need to understand and communicate the benefits that are within our grasp, because it is the benefits that engage stakeholders when change is needed. Business models are changing dramatically and education is no different. But the whole question of strategic management in education, so important to the successful achievement of change, still seems to lie under the surface. Education is not immune to change, and has to be able to manage it. The conversations indicate that there is evidence of planning, but there is equal evidence of happenchance and improvisation. The following anecdote illustrates the need for strategic thinking based on understanding the benefits:

\begin{abstract}
'One of the reasons we [switched to Sakai] is that there is an open source community of users that support the use of Sakai. Like other schools we seriously questioned whether Blackboard is the right choice at this point because it costs an awful lot of money and that was killing us; we asked how do we get support from Blackboard? Well it turns out that Blackboard had created a community of users that you could share your problems with, they get back to you and help. But I'm, like, 'Isn't that open source? That's open source isn't it? But we're paying someone to do this?' We don't want to do that, so we switched [to Sakai] in 2007'. [Senior academic, University, USA]
\end{abstract}

There are long-term operational and financial implications in decisions like these. But change is not just operational, it is fundamental; how we see knowledge and our perceptions of managing knowledge are changing, in very interesting ways:

'If something is classed as research, then one would assume that it is done in a rigorous manner and accepted by a body of scholars who are all agreed, and so if I presented a hypermedia [work] of, say, the structure of knowledge, it could be a taxonomy, some kind of graphical representation of the linkages of concepts and so on. If I found that these were accepted and integrated into the minds and work of other scholars, then the fact that I had rendered this representation of knowledge ... should be an even more compelling argument that I am a member of the research community ... and so this might be a shorthand way of avoiding writing thousands of pages'. [Learning management system manager, Business faculty, University, New Zealand]

This short monologue has profound implications. At one level we see people happily playing with, or even working with, 'mind maps'. But a mind map is just one example of how technology and systems allow us to deal with what we know in new and quite different ways. As the world still struggles to normalise and standardise the relatively simple thing that is metadata (such as the descriptive data about academic papers and books: author names, journal titles, publishers and so on) we have little prospect of normalising and standardising what knowledge is; but we are already a long, long way from the Dewey decimal classification system, and with these portentous issues in mind we have to agree that this all becomes highly strategic.

In summary, there is useful evidence of the potential benefits of information technology and information management here, but grasping them requires strategies that might redefine what education actually is.

\section{Strategy}

The stimulus that comes from new technologies drives much strategic change, in organisations of all kinds. Business, government and civil society all benefit from new ways of working and communicating. The answer, we are told, is to align our technology and organisational strategies:

[Luftman] is an American academic, former consultant. He did some quite interesting work on alignment ... [but] he has found 'the least aligned industry is education'! The reason is that there are multiple stakeholders with frequently conflicting goals, whereas in other businesses there are not. [In education] it's administration versus academics, academics versus students, and students versus administration. [Learning Chair, University, Canada]

Here is interesting evidence (Luftman 2003) that education really is late in understanding and adopting strategic management, but is strategic alignment 'doable' in education? Academic management is not universally known for its ability to manage everything well, and academics allow themselves the luxury (or is it a privilege?) to do what they want to do, much of the time. We have found that there are significant benefits to be gained, but tightening up the management of the many dependencies between technology acquisition and strategic success is what is needed, and this is indeed challenging.

At the heart of the confusion involved in aligning technology and strategy is the proper management of information, and of the information-enabled processes that we undertake to deliver educational value. 


\section{Results}

The selected evidence presented here is from eight conversations and is therefore hardly definitive, but it helps us to adjust our thinking and achieve a balance. There is evidence of a range of stakeholders, and the ways in which they can help or hinder. There is evidence of a range of benefits that are sought, and we begin to see different kinds of benefit for the different stakeholders. Finally, even in these developed countries we see only passing signs of true strategic planning, but some evidence that planning does lead to better outcomes.

We are left with the most important question: does strategic planning help to deliver the benefits of information management in education?

It seems to depend on circumstances. Despite a concern for the ability of educational institutions to manage their technologies well, there is evidence that when educational organisations do get their strategic act together there are real benefits: for the teachers, for the learners and for other stakeholders. However, it is clear that the circumstances of the institution determine the nature of the strategy or strategies adopted.

\section{Strategies for innovation, radical change and operational excellence}

A closer examination of the specific evidence about strategies reveals thinking at three difference levels:

- A desire to innovate and discover new opportunities.

- A commitment to undertake radical organisational change.

- A simple ambition to work efficiently and effectively.

The high school in New Zealand is a good example of innovation. It is a new school with no baggage from its history that it has to deal with: it has new buildings, new ideas and new resources. Most importantly, its management meets regularly and drives the further development and refinement of the ideas by managing 're-invention':

One of the good things about the school is that it is totally new ... it's quite revolutionary! In the average school if something doesn't work people turn around and say 'these new ideas, new systems do not work ...' and go back to the old way ... Whereas in our case we have a strong tendency to say 'OK, it doesn't work, we have to re-invent ourselves'. The old way is not physically available, so you have to say 'right, let's re-invent ourselves'. [Technology teacher, High school, New Zealand]

This is real innovation, untrammelled by the baggage of a history.

The university in Auckland reveals quite a long history of careful and progressive management of its information technology, and although there are some signs of traditionalist thinking, the business school that contributed to these conversations has magnificent buildings and luxurious facilities within them. They seem to have close associations with business that keep their feet on the ground, and the management imperative probably rubs off when they meet and talk to their business friends. They are certainly making strategic use of the latest technologies:

There is a thing called 'infopath' which is building what appears to be a document but is actually a series of attributes that can be queried and mailed - this goes as input to Sharepoint and so basically common stuff - course description, course reports - all that kind of thing now sits in a repository in Sharepoint and it's versioned, and we can look at and across all of the documentation that used to be hard copy, and start to understand what it is that we can do with it. And [yet] we don't have integrated systems. Or the systems we have are not integrated enough. [Learning management system manager, Business faculty, University, New Zealand]

This looks like a strategically capable university that has a long history of proactively managing radical change (in relation to traditional university practice).

The university in the United States adopts a very traditional stance, but is highly aware of trends and has active programmes in place to consider its options and maintain its competitive standing (and, make no mistake, it is in a very competitive situation):

I think the challenge may be the senior leadership are always having to face those [competitive] issues and prioritise ... especially at a time of economic strain. Recently we did two successive rounds of cuts so, you see we are not a public institution and yet we are constrained by financial changes in the market. We rely on an endowment for certain spending. [Senior academic, University, USA]

Almost all of the strategic management effort in this institution is directed at operational efficiency, and maintaining the critical services that good students expect.

And so we find evidence of 'innovative', 'radical' and 'operational' strategies.

In the evidence, there are 82 instances of conversation that were coded as having a direct link to strategy; these are subdivided into the three subdivisions of strategy (see Figure 5). It is found that the majority of the instances reveal an operational approach to strategy (efficiency and effectiveness), rather than being truly strategic (grasping opportunities and managing them proactively) or innovative (making new opportunities through experimentation and invention)

One might conclude that any educational institution that is willing and able to innovate will easily stand out from the crowd and ease itself much more successfully into the future, provided it can manage the innovation (and the consequential changes) well. Those that cannot innovate must focus on what is possible: being distinguished by doing some things very well and in different ways, or being economical by means of excellent administration and low-cost 


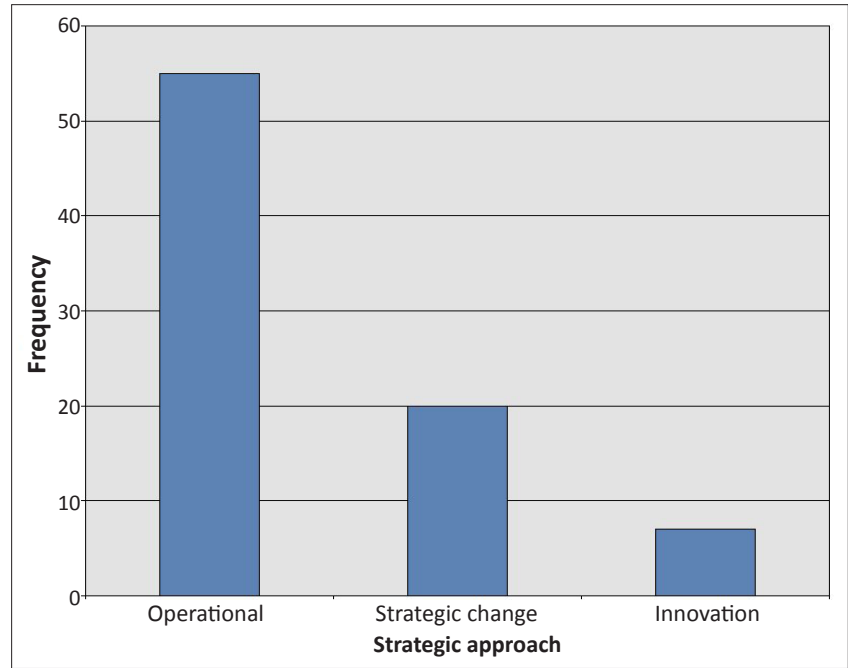

FIGURE 5: Analysis of management.

educational services. Technology can contribute to any of these, but doing more than one at the same time is confusing for staff and for students.

\section{Implications of the work}

This work began with the observation that education in South Africa is in a poor condition, and that there has been substantial investment in information technology that was intended to improve the quality of education, with variable results. Rather than looking at the problem from the 'bottom up', as often happens when looking at the impact of technology on pedagogy and didactics, it was decided to look at it from the 'top down', with a management perspective, and borrowing ideas from the domain of regular business management, and looking at information management broadly, not only as technology and systems:

- International experience confirms the importance of stakeholders, and the need to understand their roles and their expectations. Different stakeholder groups are looking for different benefits, and these differences need to be managed. South Africa presents special challenges relative to international experience, because of issues of language, ethnicity and context, thus making a strategic approach to information management doubly important.

- A further important issue, related to stakeholder expectations, is that the derived benefits of information management can be simple (leading to improved efficiency), complex (requiring institutional change in the cause of effectiveness) or innovative (new kinds of teaching and learning through evolutionary thinking). These different kinds of benefit cannot be achieved in parallel, they are conflicting. It is necessary to manage strategically by admitting and negotiating the benefits that are most appropriate to a situation. In most cases (from the conversations), the expected benefits were operational; in South Africa that might not be enough and more radical ideas might be needed.

- Perhaps most important to South Africa is that boundaries are dissolving, and education is becoming an international phenomenon. That might be of little interest to rural South African learners who are stuck in the traditional educational paradigm, but it is exacerbating the divide between the 'haves' and the 'have-nots'.

\section{Conclusion}

What can be seen from this analysis of international conversations, perhaps predictably, is that technology is both a threat and an opportunity. But there is evidence that education is - through the introduction of technology - becoming a very international business. This challenges every country to take stock of what it needs to do, where its educational capability and resources might come from and how they might be managed.

So will strategic planning help to deliver the benefits of information technology investments through good information management? We do not know; it is not yet clear that this is the case, despite the evidence found here. As we proceed further into the digital age, we need to be conscious that:

- ICT itself is, first and foremost, a cost driver not a benefit driver: benefits come from improved processes that deliver improved organisational performance. But education is increasingly recognised as an incremental process that is driven by the individual learner, not by the institution.

- It is necessary to be certain about (and committed to) the delivery of benefits to all stakeholders, not just teachers and learners, but the tensions between stakeholders are real and impede a simple agreement about what the benefits actually are, as argued by Luftman (2000, 2003). Truly strategic thinking sets targets, manages demand and supply and ensures that all our investments in ICTs are directed at real benefits, for real stakeholders.

- Education systems are a part of a global ecology that is rapidly eliminating geographical and cultural boundaries, with real consequences for the prospects of our young populations. Even the best strategy managers struggle to deal with the huge gulf of understanding that can arise when cultures clash.

Life in education is full of surprises and so not everything can be planned. Improvisation is the stuff of innovation, and so teaching practice must not be constrained. But the balance between planning and improvisation must be understood and managed. What cannot be tolerated in countries and regions where education is desperately needed is the chaotic and anarchistic behaviour that might result if the adoption of ICTs in education is not well managed, in ways to deliver real benefits to the most important stakeholder: the learner.

\section{Acknowledgements Competing interests}

The authors declare that they have no financial or personal relationship(s) that may have inappropriately influenced them in writing this article. 


\section{Authors' contributions}

A.B. (University of the Western Cape) undertook research design and data collection, and drafted the article. I.M.V. (University of the Western Cape) mentored and contributed significantly to the finalisation of the article.

\section{References}

Anderson, J., Van Weert, T., Buettner, Y., Duchâteau, C. \& Fulford, C., 2002, Information and communication technology: A curriculum for schools and programme of teacher development, UNESCO, France.

Angell, I., 2000, The new barbarian manifesto: How to survive the information age, Kogan Page, London, England.

Baets, W., 1992, 'Aligning information systems with business strategy', The Journa of Strategic Information Systems 1(4), 205-213. http://dx.doi.org/10.1016/0963$8687(92) 90036-V$

Baker-Eveleth, L., Eveleth, D.M., O'Neill, M. \& Stone, R.W., 2007, 'Enabling laptop exams using secure software: Applying the technology acceptance model', Journal of Information Systems Education 78, 413-420.

Barron, A.E., Kemker, K., Harmes, C. \& Kalaydijian, K., 2003, Large-scale research study on technology in K- 12 school: Technology integration as it relates to national technology standards', Journal of Research on Technology in Education 35, 489508. http://dx.doi.org/10.1080/15391523.2003.10782398

Bhusry, M. \& Ranjan, J., 2012, 'Enhancing the teaching-learning process: A knowledge management approach', International Journal of Educational Management 26(3), 313-329. http://dx.doi.org/10.1108/09513541211213372

Botha, N., 2009, 'Analysis and summary of the research themes of the concept papers received in response to the two national calls from the NRF, National Research Foundation', viewed 14 August 2010, from http://www.nrf.ac.za/files/ Document\%203-Summary\%20research\%20themes\%20national\%20research\%20 agenda\%20June\%2009\%20_2_.pdf

Brown, C., 2010, 'Excavating the meaning of information and communication technology use amongst South African university students: A critical discourse analysis', doctoral thesis, Dept. of Information Systems, University of Cape Town.

Bytheway, A., 1998, 'Academic CS/IS Infrastructure in South Africa: An exploratory stakeholder perspective, Proceedings of SAICSIT November 1998', Cape Town, South Africa.

Bytheway, A., 2004, ICT in Higher Education research project, University of the Western Cape, Bellville.

Bytheway, A., 2004, 'Information management body of knowledge (IMBOK)', Cape Technikon, Cape Town.

Bytheway, A., Sadeck, O., Dumas, C., Chigona, W., Chigona, A., Mooketsi, B. \& Fanni, F., 2010, 'Integrating ICTs into the classroom: Assisting teachers in disadvantaged primary schools', Proc 2010 eSkills Summit, Cape Town, South Africa.

Bytheway, A., 2011, 'Assessing Information Management Competencies in Organisations', Electronic Journal of Information Systems Evaluation 14(2), 179192.

Bytheway, A., 2013, 'Qualitative Research without money: Experiences with a home-grown Qualitative Content Analysis tool', The Journal of Community Informatics 9(4)

Chatham, R. \& Patching, K., 2000, Corporate politics for IT managers: How to get streetwise, Butterworth-Heinemann, Newton.

Chatterji, S., 2007, 'Bridging business and IT strategies with enterprise architecture: Realising the real value of business-IT alignment', Information Systems Control Realising the real
Journal $3,1-2$.

Chigona, W., Bladergroen, M., Cox, S., Dumas, C. \& Van Zyl, I., 2011, 'Educator discourses on ICT in Education', in E-Skilling for Equitable Prosperity and Global Competiveness, South African Department of Communications, East London, South Africa.

Davids, Z., 2009, 'The educators' perspective on the factors that influence the success of ICT school initiatives within the Western Cape', master's thesis, University of Cape Town, South Africa.

DeLone, W.H. \& McLean, E.R., 1992, Information systems success: The quest for the dependent variable', Information Systems Research 3(1), 60-95. http://dx.doi. org/10.1287/isre.3.1.60
DeLone, W.H. \& McLean, E.R., 2003, 'The DeLone and McLean model of information systems success: A ten-year update', Journal of Management Information Systems 19(4), 9-30.

Edwards, C. \& Peppard, J., 1997, 'Operationalizing strategy through process', Long Range Planning 30(5), 753-767. http://dx.doi.org/10.1016/S00246301(97)00056-3

Hardman, J. \& Paucar-Caceres, A., 2010, A soft systems methodology (SSM) based framework for evaluating managed learning environments', Systemic Practice and Action Research 24(2), 165-185. http://dx.doi.org/10.1007/s11213-010-9182-4

Henderson, J.C. \& Venkatraman, N., 1993, Strategic alignment: Leveraging information technology for transforming organizations', IBM Systems Journal 32(1), 4-16. http://dx.doi.org/10.1147/sj.382.0472

Jansen, J., 2012, 'Seven costly mistakes', Times Live, viewed n.d., from http://www. timeslive.co.za/opinion/columnists/2012/04/05/seven-costly-mistakes

Kearns, G.S. \& Lederer, A.L., 2000, 'The effect of strategic alignment on the use of ISbased resources for competitive advantage', The Journal of Strategic Information Systems 9(4), 265-293. http://dx.doi.org/10.1016/S0963-8687(00)00049-4

Knights, D. \& Murray, F., 1994, Managers divided, John Wiley, Chichester.

Koch, A., 2006, 'A conceptual model for a Co-operative Education Management system for tertiary institutions in South Africa', doctoral thesis, Cape Peninsula University of Technology, Cape Town, South Africa.

'Labour's computer blunders cost $£ 26,326$ bn', The London Independent, viewed 24 August 2010, from http://www.independent.co.uk

Luftman, J., 2000, 'Assessing business-IT alignment maturity', Communications of the Association for Information Systems 4, 1-51.

Luftman, J., 2003, 'Assessing IT/business alignment', Information Systems Management 20(4), 9-15. http://dx.doi.org/10.1201/1078/43647.20.4.20030901/77287.2

Madiba, M., 2009, 'Investigating design issues in e-learning', doctoral thesis, Dept. of Information Systems, University of the Western Cape, Bellville, South Africa.

Maslin, N., 1990, The intelligent island, television broadcast, BBC, London.

Mason, R.O. \& Mitroff, I.I., 1973, 'A program for research on management information systems', Management Science 19(5), 475-487. http://dx.doi.org/10.1287/ mnsc.19.5.475

McFarlan, F.W., 1984, 'Information technology changes the way you compete', Harvard Business Review 62(3), 98-103.

Michael, S.O., 1998, 'Best practices in information technology (IT) management: insights from K-12 schools' technology audits', International Journal of Educational Management 12(6), 277-288. http://dx.doi.org/10.1108/09513549810238020

Moloi, K., 2007, 'An overview of education management in South Africa', South African Journal of Education 27(3), 463-476.

Motala, E., 2009, Guidelines informing the NRF's choices and priorities for Education Research Funding: A report prepared pursuant to the NRF's regional workshops Research Funding: A report prepared pursuant to the NRF
held during October and November 2009, NRF, Pretoria.

Omona, W., Van der Weide, T. \& Lubega, J., 2010, 'Using ICT to enhance knowledge management in higher education: A conceptual framework and research agenda', International Journal of Education and Development Using ICT 6(4), 83-101.

Rahimi, F., 2010, 'The role of information and communication technology (ICT) in a higher education institution: With specific reference to disadvantaged students, cultural aspects and motivation', doctoral thesis, University of Pretoria, South Africa.

Republic of South Africa, 2004, White paper on education, Government Printers, Pretoria, South Africa.

Shirky, C., 2008, Here comes everybody: the power of organizing without organizations, Penguin, New York.

Strauss, A.L. \& Corbin, J.M., 1998, Basics of qualitative research: Techniques and procedures for developing grounded theory, Sage Publications, Thousand Oaks.

Uys, P., 2007, 'Enterprise-wide technological transformation in higher education: The LASO model', International Journal of Educational Management 21(3), 238-253. http://dx.doi.org/10.1108/09513540710738683

Venkatesh, V., Morris, M.G., Davis, G.B. \& Davis, F., 2003, 'User acceptance of information technology: Toward a unified view', MIS Quarterly 27, 425-478.

Ward, J. \& Daniel, E., 2005, Benefits management: Delivering value from IS and IT investments, Wiley, Chichester.

Ward, J. \& Peppard, J., 2002, Strategic planning for information systems, 3rd edn., Wiley, Chichester.

Zachman, J.A., 1987, 'A framework for information systems architecture', IBM Systems Journal 26(3), 590-616. http://dx.doi.org/10.1147/sj.263.0276 